\title{
O processo sucessório em propriedades de produtores de leite nos municípios de Coronel Xavier Chaves e Silveirânia, em Minas Gerais ${ }^{1}$
}

\author{
Júlio César Mendes de Souza², Ana Louise de Carvalho Fiúza3, Cláudia Maria Miranda de Araújo Pereira \\ Nora Beatriz Presno Amodeo 5
}

\section{RESUMO}

O objetivo deste estudo foi identificar os fatores que influenciam a presença de sucessores, em unidades familiares de produção de leite nos Municípios de Coronel Xavier Chaves e Silveirânia, em Minas Gerais. Utilizou-se, como referencial teórico, a influência dos valores tradicionais, e daqueles relacionados com a modernidade, no processo sucessório. Tomou-se, como hipótese, o fato de que o nível tecnológico, o tamanho da propriedade, o acesso ao crédito, a proximidade com o centro urbano e a escolaridade poderiam influenciar a presença do sucessor nas unidades produtoras de leite. Em termos de procedimentos metodológicos, trabalhou-se, nesta pesquisa, com a perspectiva comparativa entre produtores de leite de dois municípios mineiros que apresentavam níveis tecnológicos diferentes, entre si. Utilizou-se o método de levantamento com coleta de dados em campo, por meio da aplicação de 83 questionários semiestruturados a uma amostra de produtores de leite de caráter familiar. Para análise dos dados, utilizaram-se os testes $t$, qui-quadrado e de regressão. Os resultados não confirmaram a hipótese de que o nível de tecnologia seria fator interveniente no processo sucessório entre produtores de leite, porém se confirmaram as outras quatro hipóteses.

Palavras-chave: herança, pecuária leiteira familiar, regressão.

\section{ABSTRACT \\ The succession process on milk farms in the municipalities of Coronel Xavier Chaves and Silveirânia in Minas Gerais State, Brazil}

This study aimed to identify the factors that influence the presence of successors in milk production family units in the municipalities of Coronel Xavier Chaves and Silveirânia, in Minas Gerais. The theoretical reference point used was the influence of traditional values and values related to modernity on the succession process. The hypotheses were that the technological level, farm size, access to credit, the proximity to the urban center and schooling could influence the presence of the successor in milk production units. In methodological terms, this research worked, with a comparative perspective between dairy farmers in the two municipalities, which had different levels of technology. The survey data collection in the field used the application of 83 semi-structured questionnaires to a sample of family milk producers. Data was analyzed by t tests, chi-square and regression. The results did not confirm the hypothesis that the technology would be an intervening factor in the succession process of milk producers, but confirmed the four other hypotheses.

Key words: inheritance, dairy farming family, regression.

\footnotetext{
Recebido para publicação em 25/10/2012 e aprovado em 03/06/2013.

${ }^{1}$ Trabalho extraído da dissertação de mestrado do primeiro autor.

${ }^{2}$ Bacharel em Ciências Contábeis, Mestre. Departamento de Economia Rural, Universidade Federal de Viçosa, Campus Viçosa, Avenida Peter Henry Rolfs, s/n, 36570-000, Viçosa, Minas Gerais, Brasil. juliocesarms@superig.com.br (autor para correspondência).

${ }^{3}$ Licenciada e Bacharel em Ciências Sociais, Doutora. Departamento de Economia Rural, Universidade Federal de Viçosa, Campus Viçosa, Avenida Peter Henry Rolfs, s/n, 36570000, Viçosa, Minas Gerais, Brasil. louisefiuza@ufv.br

${ }^{4}$ Bacharel em Ciências Econômicas, Doutora. Instituto Federal do Sudeste de Minas Gerais, Campus Barbacena, Rua Monsenhor José Augusto, 204, Bairro São José, 36205-018, Barbacena, Minas Gerais, Brasil. cmmap06@yahoo.com.br

${ }_{5}^{5}$ Engenheira-Agrônoma, Doutora. Departamento de Economia Rural, Universidade Federal de Viçosa, Campus Viçosa, Avenida Peter Henry Rolfs, s/n, 36570-000, Viçosa, Minas Gerais, Brasil.npresno@ufv.br
} 


\section{INTRODUÇÃO}

Este artigo teve por objetivo estudar o processo sucessório nas propriedades produtoras de leite, nos Municípios de Coronel Xavier Chaves e Silveirânia, em Minas Gerais. A motivação para o tema surgiu do interesse dos pesquisadores em analisar um setor de suma importância para a economia, em âmbitos local e nacional, mas que vem passando por consideráveis transformações e desafios, desde a década de 1990, quando o Estado regulava o preço e era o principal comprador de leite dos produtores. Como consequência da não intervenção estatal, novas formas de gestão e de tecnologias foram introduzidas nas propriedades produtoras de leite, provocando, por um lado, aumento na produtividade e qualidade do leite, mas gerando, por outro, novas configurações na organização da família, em torno da atividade leiteira. Um exemplo dessas transformações, na organização das propriedades produtoras de leite, pode ser observado "no fato de que, hoje, o sucessor pode morar na cidade, vistas as facilidades de deslocamento e de comunicação entre campo e cidade, principalmente, em pequenos municípios, onde o deslocamento efetiva-se de forma rápida" (Costa, 2010).

Segundo Siqueira et al. (2011), a viabilidade econômica da atividade rural brasileira é de suma importância para proporcionar retorno sobre o capital investido, a geração e distribuição de renda para as famílias do campo. Ainda, segundo esses autores, o setor é carente de políticas que garantam o acesso à infraestrutura e aos serviços sociais que condicionam a cidadania, sem comprometer as condições de dignidade para as gerações futuras.

Nesse sentido, seria importante considerar, segundo Costa (2010), que a sucessão na agricultura familiar envolve não apenas a transferência de um patrimônio e de capital imobilizado ao longo das sucessivas gerações, mas revela, também, a existência de verdadeiro código cultural, que orienta as escolhas e os procedimentos, dirigidos a garantir que, pelo menos, um dos herdeiros possa perpetuar o patrimônio familiar. Conforme Brumer (2007), os critérios sucessórios adotados pelos pais são orientados por fatores tradicionais, mas podem, também, incorporar fatores conjunturais que, de alguma maneira, a eles se impõem.

Para Toledo (2008), os filhos de produtores rurais possuem, hoje, maior acesso à educação, crescem com cultura diferente da de seus pais e veem nos centros urbanos melhores expectativas de vida e desenvolvimento, do que as do campo. Contudo, isso não significa que a atividade leiteira, bem como a propriedade familiar, deixarão de constituir campo de possibilidade para a concretização dos novos processos sucessórios nas unidades produtoras de leite. O Censo Agropecuário de 2006, publicado em 2009 , indica que os agricultores familiares ${ }^{6}$ representavam $84,4 \%$ dos produtores e eram responsáveis por $58 \%$ da produção nacional de leite, apesar de ocuparem ape- nas 24,3\% da área de estabelecimentos rurais (IBGE, 2011a). Ou seja, os números indicam que, mesmo diante das transformações por que passa o campo, as unidades produtoras de leite de caráter familiar continuam tendo grande expressividade numérica e produtiva. Todavia, as alterações de toda ordem, tecnológicas, comerciais, legais, modificam constantemente o ambiente institucional, no qual os produtores de leite estão inseridos. Por exemplo, no âmbito legal, a Instrução Normativa $N^{o}$ 51, de 18/09/ $2002^{7}$ (Brasil, 2002), fixou os requisitos mínimos a serem observados para produção, identificação e qualidade do leite cru refrigerado. Essa normativa exige o resfriamento do leite, logo após a ordenha, com a utilização de tanques térmicos. Essa exigência pôs fim ao tradicional "caminhãozinho do leite", responsável pela coleta da produção dos pequenos produtores.

Diante da dificuldade para aquisição do tanque de resfriamento do leite, observou-se, em alguns municípios, a articulação entre Associações de Produtores com a Empresa de Assistência Técnica e Extensão Rural (EMATER), no intuito de se adquirirem tanques coletivos para o armazenamento resfriado do leite produzido. A aquisição dos tanques representou, além da possibilidade de sobrevivência dos pequenos produtores de leite, a melhoria da organização entre eles. Assim, tornou-se possível aumentar a qualidade do leite e o valor pago por litro. Dessa forma, é de se esperar que a incidência de inovações legais e tecnológicas, entre outras, modifique a organização familiar na atividade produtiva.

As normatizações direcionadas à pecuária leiteira, assim como a introdução de tecnologias, como as ordenhadeiras mecânicas, os tanques térmicos para resfriamento de leite e, ainda, novos métodos de gestão, alteraram as práticas envolvidas na atividade leiteira. Essas mudanças nas práticas produtivas e de gerenciamento repercutem, nas possibilidades de manutenção da atividade e, consequentemente, nas possibilidades de se efetivarem as sucessões. Segundo Brumer (2007), Toledo (2008) e Costa (2010), o processo sucessório na propriedade rural, atualmente, apresenta mudanças, com relação ao modelo tradicional, como a diminuição do número de filhos por família e o enfraquecimento do poder paterno na estipulação de um sucessor, bem como a profissionalização das atividades agrícolas e rurais, que atua, restrin-

\footnotetext{
${ }^{6} \mathrm{O}$ termo agricultor familiar é definido pela Lei 11.326 (2006). Alguns produtores, O termo agricultor familiar é definido pela Lei 11.326 (2006). Alguns produtores,
denominados não familiares, possuem as mesmas características dos familiares; denominados não familiares, possuem as mesmas características dos familiares;
entretanto, são classificados como não familiares devido às diferenças no tamanho da propriedade, no número e na forma de contratação de empregados ou no volume produzido. Em termos científicos, contudo, essa diferenciação não se sustenta. Assim, no trabalho, não será feita distinção entre agricultores familiares e pequenos produtores, tendo em vista que eles apresentam muitas semelhanças no processo produtivo e na estrutura da propriedade.

${ }^{7}$ A Instrução Normativa $n^{\circ} 51$ foi alterada em 30/12/2011 pela Instrução Normativa ${ }^{\circ}$ 62. A principal regra já começa a valer em $1^{\circ}$ de janeiro de 2012 , quando os produtores das Regiões Sul, Sudeste e Centro-Oeste terão novos limites para Contagem Bacteriana das Resteriana Total (CBT) e Contagem de Células Somáticas (CCS). Atualmente, esses índices podem

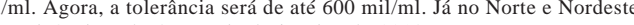
do país a mesma exigência valerá a partir de janeiro de 2013.
} 
gindo o número de propriedades aptas a atenderem às demandas do mercado. Stropasolas (2010) complementou as questões que impactam o processo sucessório, chamando a atenção para o fato de que a profissão de agricultor e, especificamente, as atividades voltadas para a pecuária de leite, restringem a disponibilidade de tempo livre, em razão da necessidade de executar trabalho, inclusive, nos finais de semana, o que se constitui em desestímulo à continuidade da atividade. Todavia, se, por um lado, os costumes e tradições envolvidos no processo sucessório perdem sua força, por outro, essa mudança não acontece com a mesma intensidade, nem da mesma forma, em todos os lugares. Assim, alguns padrões culturais ainda podem ser notados como servindo de referência para estabelecer o perfil do sucessor, como a regra do maiorato (escolha pelo filho mais velho), ou do minorato (escolha pelo filho mais novo), a preferência pelo "filhohomem", pelo filho menos escolarizado sobre o com mais ano de escola, o filho casado sobre o solteiro.

Considerando-se, assim, a influência tanto dos fatores ligados à modernidade, quanto à tradição, formularam-se cinco hipóteses: $1^{\mathrm{a}}$ ) o nível tecnológico presente constitui-se em fator interveniente na escolha de sucessor, nas unidades produtoras de leite; $2^{\mathrm{a}}$ ) o tamanho da propriedade constitui fator interveniente na presença de sucessor, nas unidades familiares de produção de leite; $3^{\text {a) }}$ o acesso ao crédito proporciona o desenvolvimento e interfere no processo sucessório dos produtores de leite; $4^{a}$ ) a proximidade com a cidade interfere na presença de sucessor nas unidades familiares de produção de leite; $5^{\text {a })}$ a escolaridade do produtor interfere no processo sucessório.

As hipóteses foram formuladas com base na teoria referente aos processos de modernização e hibridização cultural, buscando identificar os fatores intervenientes no processo sucessório dos pecuaristas de leite de caráter familiar, em dois municípios, com produtores de perfis tecnológicos diferenciados. A pesquisa foi realizada com os produtores associados dos municípios de Silveirânia, MG, localizado na mesorregião da Zona da Mata, e do município de Coronel Xavier Chaves, MG (CXC), situado na mesorregião Campo das Vertentes. Ambos os municípios têm a pecuária leiteira como a principal atividade econômica. Esses municípios foram escolhidos em razão de apresentarem algumas semelhanças e diferenças entre si.
Eles têm, em comum, sobretudo, o fato de serem pequenos, com menos de 5.000 (cinco mil) habitantes (Tabela 1), apresentarem baixa densidade demográfica e economia de base agropecuária expressiva. De diferentes têm, principalmente, a localização geográfica e o perfil tecnológico dos produtores.

Coronel Xavier Chaves localiza-se a 12 km do Município de São João Del Rei, um centro urbano com poder de atração e dinamização local, enquanto Silveirânia está cercada de outros pequenos municípios de base agropecuária, sem poder de atração populacional e dinamização da economia local. Os produtores de Coronel Xavier Chaves têm nível tecnológico mais alto, utilizando ordenhadeira mecânica e tanque de resfriamento individual, dentre outras tecnologias, em quase $100 \%$ das propriedades. Já em Silveirânia, predomina a ordenha manual e o gado é tratado no pasto, durante longo período, para minimizar os custos de produção. Essas diferenças e semelhanças entre os municípios foram determinantes para a escolha de ambos, em razão de propiciarem o teste das hipóteses formuladas.

\section{MATERIAL E MÉTODOS}

Para investigar como ocorria o processo sucessório entre os produtores familiares de leite, nos municípios de Coronel Xavier Chaves e Silveirânia, aplicaram-se questionários, cujas questões tinham objetivos descritivos e explicativos, voltados para a descrição das características socioeconômicas dos produtores, como o nível tecnológico, a renda e as formas de produção e gestão, mas, também, para a geração de dados que pudessem identificar os fatores intervenientes no processo sucessório nas unidades produtoras de leite.

Foram elaborados dois tipos de questionários, a fim de se analisarem os fatores intervenientes no processo sucessório, nas unidades produtoras de leite: um, direcionado ao gestor do estabelecimento agropecuário e, outro, direcionado aos filhos do(a) proprietário(a). No modelo aplicado ao(à) gestor(a), o questionário foi estruturado em sete partes: $1^{a}$ ) questões relativas ao perfil do produtor; $2^{\mathrm{a}}$ ) questões relativas ao nível tecnológico da atividade leiteira; $3^{\mathrm{a}}$ ) questões relativas à estrutura fundiária; $4^{\mathrm{a}}$ ) relação com a cidade; $5^{\mathrm{a}}$ ) relação com o crédito; $6^{a}$ ) nível de capacitação do produtor; $7^{\mathrm{a}}$ ) questões

Tabela 1. População rural e urbana nos Municípios de Coronel Xavier Chaves e Silveirânia, MG, 2000 e 2010

\begin{tabular}{|c|c|c|c|c|}
\hline \multirow{3}{*}{ População } & \multicolumn{2}{|c|}{ Coronel Xavier Chaves } & \multicolumn{2}{|c|}{ Silveirânia } \\
\hline & \multicolumn{2}{|c|}{ Ano } & \multicolumn{2}{|c|}{ Ano } \\
\hline & 2000 & 2010 & 2000 & 2010 \\
\hline Rural & 1502 & 1501 & 1117 & 763 \\
\hline Urbana & 1683 & 1800 & 1021 & 1429 \\
\hline Total & 3185 & 3301 & 2138 & 2192 \\
\hline
\end{tabular}

Fonte: IBGE (2011b). 
relacionadas com a sucessão no estabelecimento. No modelo aplicado aos filhos dos produtores, foram relacionadas questões sobre o perfil dos filhos e perspectivas futuras em relação ao trabalho, à moradia e à sucessão no estabelecimento agropecuário. As análises foram realizadas com o intuito de inferir a veracidade das hipóteses formuladas.

Para determinação da amostra da pesquisa, utilizou-se o método de amostragem probabilística. Para o trabalho, usou-se o valor de $50 \%$ como taxa de homogeneidade e $10 \%$ para o erro amostral. Assim, utilizando-se $95 \%$ de grau de confiança, foram entrevistados, aleatoriamente, 31 produtores em Coronel Xavier Chaves e 52 em Silveirânia. Os dados foram analisados por meio do software Statistical Package for Social Sciences (SPSS), acionando-se os seus recursos relativos à análise exploratória de dados (AED), à análise bivariada, acompanhada do teste do qui-quadrado, e à análise de regressão. Em relação a esta última, consideraram-se na análise as características socioeconômicas (o local de residência, a composição familiar, a escolaridade, etc.); o nível tecnológico (as máquinas da propriedade, o sistema de criação do gado, a forma de inseminação); a utilização de crédito e a forma de gestão da propriedade. As ferramentas empregadas podem ser pesquisadas em Hair et al. (2005), Barbetta (2008) e Triola (2008).

\section{RESULTADOS E DISCUSSÃO}

Em Silveirânia, município de pequeno porte, cercado também por outros pequenos municípios, a análise de regressão (Tabela 2) evidenciou que o fato de o produtor residir na cidade influenciava, significativa e positivamente, para que o estabelecimento tivesse um sucessor, no futuro. A participação dos filhos no processo de tomada de decisão foi outra variável que também se mostrou significativa para que houvesse sucessor na unidade produtiva de leite. O valor do crédito financiado e a renda bruta da propriedade também foram considerados significativos para o processo sucessório, porém, de forma mais leve que "a residência na cidade" e a "participação dos filhos na tomada de decisão". Isso indica que, apesar de serem significantes, o incremento do valor fi- nanciado e da renda não aumentam consideravelmente a possibilidade de sucessores.

Já em Coronel Xavier Chaves (Tabela 2), a variável residência na cidade também se mostrou significante para o processo sucessório, contudo, com influência negativa para que a propriedade viesse a ter um sucessor. Um aspecto, que poderia explicar essa influência negativa da residência na cidade sobre o processo sucessório, diz respeito ao fato de que os produtores residentes na cidade de Coronel Xavier Chaves estão muito próximos a um centro urbano, com força catalisadora, em termos de mercado de trabalho, enquanto os produtores de Silveirânia têm, na atividade agropecuária, a sua principal fonte de trabalho.

Em Coronel Xavier Chaves, o fato de os filhos participarem das decisões também se mostrou significante e positivo para o processo sucessório, bem como a idade do produtor, que foi significativa e levemente positiva, indicando que, quanto maior a idade do produtor, maior a chance de haver um sucessor escolhido. Ou seja, a sucessão não se efetiva na juventude, mas em idade próxima aos 40 anos, conforme evidenciado pelos estudos de Silvestro et al. (2001) e Stropasolas (2010). Durante a pesquisa, encontraram-se filhos entre 42 e 47 anos de idade, vivendo com os pais, o que indica tratar-se de um processo sucessório marcado pela transferência gradual de responsabilidades do patriarca ao filho sucessor, que pode vir a assumir a propriedade por volta dos 50 a 60 anos. Ao longo dos anos e das décadas, o filho sucessor, aquele que permanecer na propriedade, assumirá gradualmente maiores responsabilidades, até que estas se tornem plenas.

Observou-se, ainda, entre os produtores de leite, que $56,25 \%$ dos filhos que pretendiam assumir o lugar dos pais na propriedade não estudaram além do $2^{\circ}$ grau e que $76,19 \%$ deles gostariam de assumir a propriedade. De acordo com Delfini \& Oliveira (2009), as políticas públicas direcionadas para a educação no campo deixam de preparar jovens conscientes de sua realidade e de darem instrumental necessário para assumirem a propriedade familiar, de maneira a incrementar e diversificar suas atividades, agregando valor e garantindo melhor qualidade de vida ao grupo. O teste do qui-quadrado, com sigma igual a 0,045 , realizado com os dados dos

Tabela 2. Fatores que influenciam a presença de sucessores em unidades familiares de produção de leite, nos Municípios de Coronel Xavier Chaves e Silveirânia, MG: análise de regressão, coeficientes B e S, 2012

\begin{tabular}{llcc}
\hline Município & \multicolumn{1}{c}{ Variável } & B & Sigma \\
\hline \multirow{3}{*}{ Silveirânia } & Residência (cidade) & 2,931 & 0,027 \\
& Valor financiado & 0,000 & 0,074 \\
& Filhos que participam das decisões & 3,507 & 0,007 \\
& Renda bruta da propriedade & 0,000 & 0,085 \\
\hline \multirow{3}{*}{ Coronel Xavier Chaves } & Residência (cidade) & $-2,292$ & 0,032 \\
& Filhos que participam das decisões & 3,392 & 0,016 \\
& Idade do produtor & 0,172 & 0,025 \\
\hline
\end{tabular}

Fonte: Dados da pesquisa, 2012.

Rev. Ceres, Viçosa, v. 60, n.5, p. 603-609, set/out, 2013 
filhos dos produtores de ambos os municípios, juntos, indicou haver associação entre o fato de o filho não estudar e o de almejar ser o sucessor na propriedade (para um "p" com valor alto (>0,05), devendo-se considerar que as variáveis analisadas são independentes). Em Silveirânia, mais do que em Coronel Xavier Chaves, constatou-se que a grande maioria dos jovens $(71 \%)$ considerou o campo um bom local para residir e trabalhar. Já em Coronel Xavier Chaves, a vontade de morar no campo não chegou a $30 \%$, e a de nele trabalhar ficou em $42 \%$. Isso reforça os dados que apontam que o maior nível tecnológico da propriedade não representa fator preponderante para a efetivação do processo sucessório, entre os produtores pesquisados.

Neste sentido, constatou-se que, embora o nível tecnológico dos produtores de Coronel Xavier Chaves fosse maior, e eles próprios fossem mais produtivos que os produtores de leite de Silveirânia, com $83 \%$ tendo ordenhadeiras mecânicas, contra 32,1\% de Silveirânia; $83,7 \%$ realizando duas ordenhas diárias; contra $60,7 \%$; e os primeiros apresentarem uma média de 251 litros/dia, contra 135 litros/dia dos segundos, a análise de regressão evidenciou que o nível tecnológico não constituía fator significante para a possibilidade de existir pelo menos um sucessor na propriedade (para uma probabilidade $<0,10$, considera-se que existe associação entre as variáveis analisadas). O processo sucessório efetivava-se de forma independente do nível tecnológico, tanto em Coronel Xavier Chaves, quanto em Silveirânia.

Quando se observa que a busca pelo crédito constitui fator interveniente no processo sucessório, mas que os produtores rurais não investem nem $35 \%$ do recurso em tecnologia, valendo-se do crédito para o custeio das atividades, a exemplo da compra de insumos, percebe-se que, mesmo entre os produtores de leite de Coronel Xavier Chaves, que são mais tecnificados, a racionalidade que impera não é a da eficiência produtiva. Portanto, faz todo sentido que o nível tecnológico não se mostre determinante para o processo sucessório. Esses dados indicam que o crédito vem tornando possível os produtores de leite manterem-se na atividade.

A extensão das propriedades também pode ajudar a compreender a racionalidade, não estritamente produtiva, que permanece imperando, tanto no processo sucessório, quanto no desenvolvimento da atividade leiteira. De acordo com Romeiro (2007) e Silvestro et al. (2001), em propriedades com baixo nível tecnológico o tamanho reduzido das terras poderia ser determinante para a sua insustentabilidade econômica. Contudo, esse não era o caso. O tamanho médio das propriedades, em Silveirânia, era de 40 ha e, em Coronel Xavier Chaves, de 23 ha.

A investigação procurou, em um primeiro momento, analisar se o tamanho médio da propriedade, encontrada entre os produtores de leite de ambos os municípios interferiria na sua eficiência produtiva, considerando- se, para isso, os parâmetros estabelecidos por Gomes $(2007)^{8}$ para, em seguida, analisar se o tamanho da propriedade influenciaria no processo sucessório. O teste $t$ apresentou sigma igual a 0,185, em Silveirânia, e 0,204, em Coronel Xavier Chaves. Assim, segundo esses resultados, para os produtores de leite de Silveirânia e de Coronel Xavier Chaves o tamanho da propriedade não influenciaria na sua eficiência produtiva, ou seja, não comprometeria a sua eficiência produtiva. Talvez, o fato de o tamanho apresentar-se como viável para o desenvolvimento da atividade ajude a explicar, também, os resultados da análise de regressão, os quais evidenciaram que o aumento da área influenciava na possibilidade de o sucessor ser definido.

Em Silveirânia, mais da metade dos produtores de leite $(62,5 \%)$ recebeu parte das suas terras sob a forma de herança, quando eles já estavam próximos dos 40 anos, casados e com filhos, preenchendo os requistos para poder assumir a propriedade da família. Em ambos os municípios, a efetividade do processo sucessório mostrou-se muito boa. Em Silveirânia, havia a perspectiva de que apenas 5,8\% das propriedades fossem vendidas, contra 3,2\%, em Coronel Xavier Chaves. Constatou-se, ainda, que os atuais proprietários utilizavam a estratégia de atrasarem ao máximo a transferência da administração da propriedade ao filho sucessor. $\mathrm{O}$ fato de esperarem que o filho sucessor cuide deles durante a velhice reforça, ainda mais, a estratégia de atrasar o momento da transferência.

Há ainda, no entanto, outros fatores, para além do tamanho da terra e do uso do crédito barato no custeio da atividade, que poderiam ajudar a entender o porquê de a racionalidade produtiva, na atividade leiteira, não ser determinante para o processo sucessório, nas unidades produtoras de leite. Um dos fatores que também podem ajudar a entender como a racionalidade produtiva e a eficiência na atividade leiteira podem não ser determinantes, para a viabilidade sucessória, nas unidades produtivas pesquisadas, é a aposentadoria. Vários estudos, como os de Brumer (2002), Tonezer (2004) e Santos (2006), dentre outros, vêm apontando para a utilização dos proventos da aposentadoria no custeio das atividades produtivas.

Em Silveirânia, por exemplo, as unidades produtoras de leite não se encaixavam dentro dos critérios de eficiência produtiva, utilizados por Gomes (2007), mas 62,5\% dos produtores recebiam proventos de aposentadoria. Isso torna possível perceber que esse benefício pode, de fato, como tantos estudos vêm mostrando (Brumer, 2002; Tonezer, 2004; Santos, 2006), ser utilizado como uma forma de custeio das atividades agropecuárias, contribuin-

${ }^{8}$ De acordo com o autor, em Minas Gerais os produtores com produção na faixa de até
50 litros e de 50 a 200 litros diários operariam com prejuízo, porque a receita gerada
não seria suficiente para cobrir os custos no processo produtivo. Já os produtores com
produção acima de 200 litros diários conseguiriam obter retorno financeiro na atividade. 
do, de forma indireta, para o próprio processo sucessório, à medida que supre os déficits da atividade, mantendo e impulsionando a vida na propriedade. Esse fato pode ser corroborado pelo baixo percentual dos produtores de Silveirânia que disseram que a propriedade seria vendida $(5,8 \%)$. Nesse sentido, os rendimentos advindos da aposentadoria podem ajudar a entender o porquê de a propriedade continuar operando, com o significado de um patrimônio familiar, sem que prepondere a racionalidade produtiva.

Não se deve, contudo, confundir racionalidade produtiva com racionalidade econômica, nem supor que, nas unidades produtoras de leite, que operam com valor deficitário em termos de eficiência produtiva, não se incorpore, também na importância que tem a propriedade como patrimônio familiar a racionalidade econômica. Em Coronel Xavier Chaves, por exemplo, a percentagem das propriedades com possibilidade de sucessor era maior, justamente, no estrato com produção superior a 200 litros diários de leite. Também, 50\% das propriedades com possibilidade de sucessor apresentavam renda familiar anual superior a $\mathrm{R} \$ 30.000,00$, enquanto, em Silveirânia, $25 \%$ dos produtores recebiam renda anual abaixo de $\mathrm{R} \$ 12.000 .00$ e, 46,4\%, acima de $\mathrm{R} \$ 20.000,00$.

A racionalidade econômica não deve, todavia, ser analisada de forma fragmentada, ou seja, estudando-se uma atividade produtiva, como a leiteira, de forma isolada. É importante considerar que os pequenos agricultores produzem parte dos alimentos que consomem e ainda vendem, mesmo que pouco, o excedente. Muitos não têm gastos expressivos com insumos, em virtude de usarem os que a própria natureza oferece, a exemplo do pasto, utilizado como a principal forma de alimentação do gado por muitos produtores, principalmente de Silveirânia. Assim, seria razoável deduzir que a manutenção da propriedade poderia ser viável e racional economicamente, ainda que a renda do leite, isoladamente não desse lucro. Portanto, por trás da racionalidade patrimonial, com a valorização da terra como patrimônio familiar, a qual está presente no processo sucessório, estaria embutida, também, uma racionalidade econômica que não deixa de mostrar a importância da renda para a manutenção do patrimônio. Entretanto, essa racionalidade econômica e não especificamente produtivista deve ser compreendida no seu todo e não de forma fragmentada, priorizandose apenas determinada atividade produtiva. Considerando-se, ainda, que essas famílias não costumam gastar com aluguel, conta de água e de telefone etc., pode-se considerar que seus rendimentos permitiriam a reprodução e manutenção da unidade produtiva, dentro de uma racionalidade patrimonial, tudo isso calcado na valorização da manutenção e da transmissão da "terra como um bem da família", mas, também, pautado nos benefícios econômicos dela advindos, como a geração de alimentos e a venda de parte destes.

No que diz respeito à questão relativa ao definidor do sucessor (Tabela 3), os dados colhidos em ambos os municípios poderiam ser interpretados como tendo apresentado possível divergência entre si, visto que, em Silveirânia, o poder do pai na definição do sucessor foi

Tabela 3. Frequência dos elementos definidores da sucessão: unidades familiares de produção de leite, nos Municípios de Coronel Xavier Chaves e Silveirânia, com possibilidade de sucessor, MG, 2012

\begin{tabular}{lrrrr}
\hline Variável & \multicolumn{2}{c}{ Silveirânia } & \multicolumn{2}{c}{$\begin{array}{c}\text { Coronel Xavier } \\
\text { Chaves }\end{array}$} \\
\cline { 2 - 5 } & Freq & \% & Freq & \% \\
\hline A escolha do sucessor será feita apenas pelo pai & 12 & 42,9 & 1 & 8,3 \\
A escolha do sucessor será feita pelos pais & 5 & 17,9 & 3 & 25,0 \\
A escolha do sucessor será feita pela família & 10 & 35,7 & 5 & 41,7 \\
Sucessor será o filho mais velho & 11 & 39,3 & 4 & 33,3 \\
Sucessor será o filho mais novo & 4 & 14,3 & 1 & 8,3 \\
Sucessor será o(a) filho(a) que mais gostar da propriedade & 6 & 21,4 & 3 & 25,0 \\
Outros (genro, sobrinhos e não definiram ainda) & 7 & 25,0 & 4 & 33,3 \\
A transferência ocorrerá quando os pais tiverem renda garantida & 3 & 10,7 & 1 & 8,3 \\
A transferência ocorrerá quando o sucessor estiver preparado & 8 & 28,6 & 1 & 8,3 \\
A transferência não será realizada enquanto o proprietário estiver & & & & \\
em condições de trabalhar & 11 & 39,3 & 8 & 66,7 \\
Não definiram ainda & 6 & 21,4 & 2 & 16,7 \\
Existem terras para todos os sucessores & 11 & 39,3 & 4 & 33,3 \\
Existem terras apenas para o sucessor & 15 & 53,6 & 8 & 66,7 \\
Os filhos não sucessores receberão indenização & 12 & 42,86 & 4 & 50,0 \\
Espera que os fillhos cuidem dos pais na velhice & 17 & 60,7 & 6 & 50,0 \\
\hline
\end{tabular}

Fonte: Dados da pesquisa, 2012.

Rev. Ceres, Viçosa, v. 60, n.5, p. 603-609, set/out, 2013 
assumido mais abertamente que em Coronel Xavier Chaves, onde esse poder ficou subsumido dentro da família; contudo, a ordem que impera dentro desta segue o respeito aos desígnios paternos. Assim, ter-se-ia mais uma confluência do que uma divergência dos parâmetros sucessórios, a qual se mostra ancorada nos costumes familiares mais que nas leis, sustentando a escolha relativa "ao filho homem mais velho" para dar continuidade à missão de manter o patrimônio da família. Apesar de os gestores considerarem que as mulheres possuem as mesmas chances, nenhuma mulher foi escolhida como possível sucessora. Quanto aos que não vão se tornar sucessores, os dados apontaram que receberiam "indenizações reparatórias", enquanto, ao sucessor, caberia a responsabilidade de cuidar dos pais.

\section{CONCLUSÕES}

Confirmam-se, nesta pesquisa, as hipóteses de que o tamanho da propriedade, o acesso ao crédito, a proximidade do estabelecimento agrícola com o centro urbano e o nível de escolarização se constituíam em fatores intervenientes no processo sucessório nas unidades produtoras de leite.

Em Silveirânia, município rural, distante de centros urbanos dinâmicos, percebeu-se ser mais a força dos valores e práticas tradicionais sobre o processo sucessório, do que em Coronel Xavier Chaves, próximo de um centro urbano dinâmico. Em Silveirânia a sucessão mostrou-se ser menos condicionada pela viabilidade econômica das atividades agropecuárias, estando mais relacionada a um modo de vida tradiconal, que se sustentava à margem dos imperativos do mercado, garantidos através dos baixos custos de investimento na propriedade. Em contrapartida, em Coronel Xavier Chaves a influência dos valores e práticas típicas da sociedade capitalista se mostraram mais intervenientes sobre o processo sucessório nas unidades produtoras de leite que em Siveirânia.

Todavia, mesmo em Coronel Xavier Chaves, negou-se a hipótese de que o nível tecnológico presente em uma unidade produtiva constituiria fator interveniente na presença de sucessor nas unidades produtivas de leite. Tal fato aponta a permanência da função patrimonial e da economia de autossustentação no processo sucessório nas unidades produtivas de leite. Desta forma, constatou-se que o potencial tecnológico, típico da economia de mercado, não se mostrou como um fator determinante dentro do processo sucessório nas unidades de leite nos municípios pesquisados. Tais unidades produtoras de leite continuam tendo seu processo de renovação, através da sucessão, marcado por valores mais ligados a manutenção do patrimônio do que a geração de lucro, típica da sociedade de mercado.

\section{REFERÊNCIAS}

Brasil (2002) Ministério da Agricultura, Pecuária e Abastecimento. Instrução Normativa $\mathrm{n}^{\circ} 51$, de 18 de setembro de 2002. Dispõe sobre regulamentos técnicos de produção, identidade, qualidade, coleta e transporte de leite. Diário Oficial da União, Brasília, 20 de setembro de 2002. Seção 1, p.13-22.

Barbetta PA (2008) Estatística aplicada às Ciências Sociais. $7^{\mathrm{a}}$ ed. Florianópolis, Editora da UFSC. 315p.

Brumer AA (2007) Problemática dos jovens rurais na pósmodernidade. In: Carneiro MJ \& Castro EG (Eds.) Juventude rural em perspectiva. Rio de Janeiro, Mauad X. 312p.

Brumer A (2002) Previdência social rural e gênero. Sociologias, $4: 50-81$.

Costa MAS (2010) Fatores econômicos e sociais da sucessão na agricultura familiar: um estudo sobre o oeste catarinense. Dissertação de Mestrado. Universidade Federal de Viçosa, Viçosa. 159p.

Delfini ST \& Oliveira JTA (2009) Agricultura familiar e empreendedorismo: análise e avaliação do programa de formação de jovens empresários rurais (PROJOVEM). Revista Ceres, 56:719-729.

Gomes ST (2007) Ponto de nivelamento na produção de leite. Disponível em: <http://www.ufv.br/der/docentes/stg/stg_artigos/A r t_203\%20 $\% 20 P O N T O \% 20$ DE $\% 20$ NIVELAMENTO $\% 20$ NA\%20PROD U \% C $7 \%$ C 3 O \% 20 D E \% 20 L E I T E \% 20 ( 29 - 10 2007).pdf>. Acessado em: $1^{\circ}$ de junho de 2012.

Hair JF, Babin B, Money AH \& Samuel P (2005) Fundamentos de métodos de pesquisa em Administração. Porto Alegre, Bookman. $471 \mathrm{p}$.

IBGE - Instituto Brasileiro de Geografia e Estatística (2011a) Disponível em: <http://www.ibge.gov.br/home/presidencia/noticias/noticia_visualiza.php?id_noticia=1766>. Acessado em: 13 de maio de 2012.

IBGE - Instituto Brasileiro de Geografia e Estatística (2011b) Disponível em: <http://www.ibge.gov.br/cidadesat/ topwindow.htm?1>. Acessado em: 19 de maio de 2012.

Romeiro AR (2007) Meio ambiente e dinâmica de inovações na agricultura. $2^{\text {a }}$ ed. São Paulo, Annablume/Fapesp. 272p.

Santos JR (2006) Previdência rural e suas interações com a realidade local: impactos territoriais em São José do Norte-RS. Dissertação de Mestrado. Universidade Federal do Rio Grande do Sul, Porto Alegre. 332p.

Silvestro ML, Abramovay R, Mello MA, Dorigon C \& Baldisserta IT (2001) Os impasses sociais da sucessão hereditária na agricultura familiar. Florianópolis, Epagri. 120p.

Siqueira HM, Souza PM \& Ponciano NJ (2011) Café convencional versus café orgânico: perspectivas de sustentabilidade socioeconômica dos agricultores familiares do Espírito Santo. Revista Ceres, 58:155-160.

Stropasolas VL (2010) Processo de socialização das crianças nas comunidades rurais. In: IV Encontro da Rede de Estudos Rurais, Curitiba. Anais, UFPR. p.01-14.

Toledo ENB (2008) A juventude rural e os desafios sucessórios nas unidades familiares de produção. Disponível em: <http://www.reluita.org/agricultura/desafios_juventude_rural.htm >. Acessado em: 26 de julho de 2012.

Tonezer C (2004) Idosos Rurais de Santana da Boa Vista - Rio Grande do Sul: efeitos da cobertura previdenciária. Dissertação de Mestrado. Universidade Federal do Rio Grande do Sul, Porto alegre. $167 \mathrm{p}$.

Triola MF (2008) Introdução à estatística. Rio de Janeiro, LTC. $656 \mathrm{p}$.

Rev. Ceres, Viçosa, v. 60, n.5, p. 603-609, set/out, 2013 